\title{
An In Silico Temperature Sensitivity Study of the Pyrolysis of Beech, Ailanthus and Spruce
}

\author{
Joshua O. Ighalo ${ }^{1 \star}$, Adewale George Adeniyi ${ }^{{ }^{* *}}$
}

\author{
${ }^{1}$ Department of Chemical Engineering, Faculty of Engineering and Technology, University of Ilorin, Ilorin, P. M. B. 1515, NIGERIA \\ *Corresponding Author: oshea.ighalo@yahoo.com \\ **Corresponding Author: adeniyi.ag@unilorin.edu.ng
}

Citation: Ighalo, J. O. and Adeniyi, A. G. (2020). An In Silico Temperature Sensitivity Study of the Pyrolysis of Beech, Ailanthus and Spruce. European Journal of Sustainable Development Research, 4(4), em0137. https://doi.org/10.29333/ejosdr/8407

\begin{tabular}{|c|c|}
\hline ARTICLE INFO & ABSTRACT \\
\hline Received: 12 Apr. 2020 & In the current investigation, a temperature sensitivity analysis of hard and softwood pyrolysis was conducted on \\
\hline Accepted: 3 Jun. 2020 & $\begin{array}{l}\text { an in silico platform. The selected samples were beech (hardwood), ailanthus (soft hardwood) and spruce } \\
\text { (softwood). Upon the successful development of the model on ASPEN Plus v8.8, the results of the model prediction } \\
\text { showed that the yield of bio-oil reduced with a rise in process temperature. Beech had the highest bio-oil yield of } \\
\text { the feedstock investigated. At } 350^{\circ} \mathrm{C} \text {, oil yield was } 36.72 \%, 35.13 \% \text { and } 32.89 \% \text { for beech, ailanthus and spruce } \\
\text { respectively. The syn-gas yield was } 39.99 \%, 38.25 \% \text { and } 35.82 \% \text { and bio-charyield was } 45.44 \%, 47.58 \% \text { and } 50.77 \% \\
\text { for beech, ailanthus and spruce respectively (at } 650^{\circ} \mathrm{C} \text { ). For the entirety of the temperature range studied, a gentle } \\
\text { fall in char yield was observed for all feedstock type (though more significant at temperatures above } 500^{\circ} \mathrm{C} \text { ). The } \\
\text { model also predicted the yield of volatiles (bio-oil and syn-gas) to be higher for the hard and soft hardwood than } \\
\text { for the softwood and this was vice versa for the char yield. }\end{array}$ \\
\hline
\end{tabular}

Keywords: ASPEN Plus, Pyrolysis, Beech, Spruce, Ailanthus

\section{INTRODUCTION}

In a bid to combat climate change and foster energy and environmental sustainability, research interests in forest residues as a renewable energy source is on the rise (Abdelouahed et al., 2012; Hosseinpour et al., 2018). The utilisation of fossil fuels has resulted in two-thirds of the global anthropogenic $\mathrm{CO}_{2}$ emissions (Mohan et al., 2006) while the use of bio-fuels has significantly decreased the emission of green-house gases (Sharma et al., 2015). Many thermochemical processes can be used to recover energy from both natural and derived biomass amongst which are pyrolysis (Arregi et al., 2016; Kan et al., 2016), gasification (Block et al., 2018; Gu et al., 2018), steam reforming (Santamaria et al., 2018; Valle et al., 2018), combustion (Emadi et al., 2017; Gani and Naruse, 2007), hydrogenation and liquefaction (Goyal et al., 2008). Pyrolysis is considered as a popular and important technique for the thermochemical conversion of biomass (Adeniyi and Ighalo, 2020). Several research efforts have been channelled towards different aspects of the pyrolysis of wood.

Process simulation are important because they can be used to study chemical processes on in silico (computer-based) (Dabiri Atashbeyk et al., 2018; Moradi et al., 2014) and mathematical (Khadem-Hamedani et al., 2015; Torabi et al., 2016) platforms. The modelling of thermochemical conversion processes can be used to achieve process optimisation (Darvishi et al., 2016). Several simulation models have been prepared for soft and hardwood pyrolysis but none has taken the approach used in the current paper whilst considering the biomass samples in question (Di Blasi, 2008; Sinha et al., 2000).

Onarheim et al. (2014) simulated the fast pyrolysis of pinewood on ASPEN (Advanced System for Process Engineering) Plus. Peters et al. (2015) conducted a simulation and life cycle assessment of the fast pyrolysis of poplar wood also ASPEN Plus. Peters et al. (2013) prepared a predictive model of pinewood on ASPEN Plus using a kinetic approach. Biomass has three major polymeric constituents which are lignin, hemicellulose and cellulose (Qu et al., 2011). These constituents possess very different thermal behaviours (Asmadi et al., 2011; Collard and Blin, 2014). The nature (in terms of ratio) of the composition of these building-blocks in the wood feedstock will influence their overall behaviour in the pyrolytic system and the product distribution and yield.

Using a variety of approaches that takes into cognisance this basis, this research team have examined the pyrolysis of banana residues (Adeniyi et al., 2019c; Ighalo and Adeniyi, 2019), sugarcane bagasse (Adeniyi et al., 2019a) and rice husk (Adeniyi et al., $2019 \mathrm{~b}, 2019 \mathrm{e}$ ). Within the scope of the authors' exhaustive search, an in silico study for the pyrolysis of Beech, Ailanthus and Spruce are unreported except for the recent paper by the research group (Adeniyi and Ighalo, 2019a). This is an important novelty of this paper. The study by Adeniyi and Ighalo (2019a) observed an optimum bio-oil yield of $62.8 \%$ for beech wood, $58.3 \%$ for Ailanthus 
Table 1. Composition Analysis of Beech, Ailanthus and Spruce wood samples (Adeniyi and Ighalo, 2019a; Demirbaş, 1997)

\begin{tabular}{cccc}
\hline & Beech wood & Ailanthus wood & Spruce wood \\
\hline & \multicolumn{2}{c}{ Proximate analysis (wt\%) } & 28.3 \\
\hline Fixed Carbon & 24.6 & 24.8 & 70.2 \\
\hline Volatile Matter & 74 & 73.5 & 1.5 \\
\hline Ash & 0.4 & 1.7 & 7.6 \\
\hline Moisture & 7.4 & 8.1 & 51.9 \\
\hline Ultimate/Elemental analysis (wt\% moisture-free) & 6.1 \\
\hline Carbon & 49.5 & 49.5 & - \\
\hline Hydrogen & 6.2 & 6.2 & 40.9 \\
\hline Sulphur & - & - & 0.3 \\
\hline Oxygen & 41.2 & 41 & 1.5 \\
\hline Nitrogen & 0.4 & 0.3 & \\
\hline Ash & 1.4 & 1.7 & 50.8 \\
\hline Cellulose & \multicolumn{1}{c}{ Chemical analysis (wt\%) } & \\
\hline Hemicelluloses & 46.7 & 21.2 \\
\hline Lignin & 45.8 & 26.6 & 27.5 \\
\hline Ash & 31.8 & 26.2 & 0.5 \\
\hline
\end{tabular}

and $54.2 \%$ for spruce wood. However, the temperature sensitivity on the product distribution was not investigated. This is an important aspect of pyrolysis investigation as it determines the theoretical optimum ahead of experimental studies. The distinctive novelty of this paper is to determine the theoretical temperature optimum for the pyrolysis of beech, ailanthus and spruce.

As a sequel to that investigation, this study utilised the validated ASPEN Plus model of Adeniyi et al. (2019e) to evaluate the temperature sensitivity of the three biomass feedstock. The samples selected were beech (hardwood), ailanthus (soft hardwood) and spruce (softwood). A key aspect of process systems engineering is investigating the effects of process variables on chemical process systems in both the real and in silico domains (Adeniyi and Ighalo, 2020) and this study helps in fulfilling part of this objective. Furthermore, this study is important as it can help gain true insight to the potentials of the feedstock for the production of bio-oil via the pyrolysis thermochemical conversion process free of extraneous factors and it comes at a time when research interest in such renewable energy technologies is on the rise. The reason for the choice of feedstock that is Beech wood is hardwood; Ailanthus wood is a soft hardwood while spruce is a softwood. This gives a good representative for each wood type.

\section{METHODOLOGY}

Much details of the underlying thermodynamics theories, simulation component list and accompanying are process integration and description steps are exactly same as discussed elsewhere (Adeniyi et al., 2019e). However, the information on the proximate and ultimate analysis of the biomass is needed to model the feedstock in the simulation. These are presented in Table 1. PR-BM (known as Peng-Robinson with Boston-Mathias alpha function equation of state) was implemented as the global calculation method for the process simulation. The method is accurate and is an improvement of the Peng-Robinson equation because there is an alpha function. The alpha function is a temperature-dependent parameter that improves the correlation for the vapour pressure of pure components at very high temperatures. It is suitable for pyrolysis because the process involves relatively high temperatures. It and has been utilised in previous studies (Adeniyi et al., 2019c; Ighalo and Adeniyi, 2020) where pyrolysis simulation was done on ASPEN plus. The overall component list consisted of acetic acid, ethylene glycol, ethanol, phenol, water, propanol, acetaldehyde, acetone, formaldehyde, propionic acid, xylan, methyl acetate, pyrrole, ethyl formate, carbon graphite, propionic acid, formic acid, methanol, hydrogen sulphide, carbon monoxide, methane, ethane and hydrogen and silicon oxide as listed in Adeniyi et al. (2019e).

The model on ASPEN Plus v8.8 can be described as a sequential-modular one. The concept of sequencing means that the order of performance of a task is designated in such a way as to assure the best possible use of available inputs (Licker, 2003). It is sequential in the sense that the output values of a module serve as the input values to the next module in the sequence (a blockby-block computation approach). The process flow diagram utilised in a previous study was implemented (Adeniyi et al., 2019e). This is shown in Figure 1. The current simulation is one that runs based on the minimisation of Gibbs free energy thermodynamic calculation method (Adeniyi and Ighalo, 2019b; Adeniyi et al., 2019f). The results obtained are discussed in the foregoing section. The model takes into cognisance the differences in the in cellulose, hemicellulose and lignin content of the biomass and the approach is described in Adeniyi et al. (2019e). Furthermore, several assumptions were implemented in the process simulation. the particle sizes of the feedstock were not considered in the simulation. All the moisture content of the biomass feedstock was considered as either the water content in the liquid product or as water vapour traces in the initially evolved gaseous product. The char was considered to be composed of a solid stream alone. The process flow sheet and simulation assumptions are the same as those discussed elsewhere (Adeniyi et al., 2019e). The temperature range selected for the study was between $350^{\circ} \mathrm{C}$ and $650^{\circ} \mathrm{C}$ because this is the region of the disintegration of biomass constituents (Collard and Blin, 2014). 


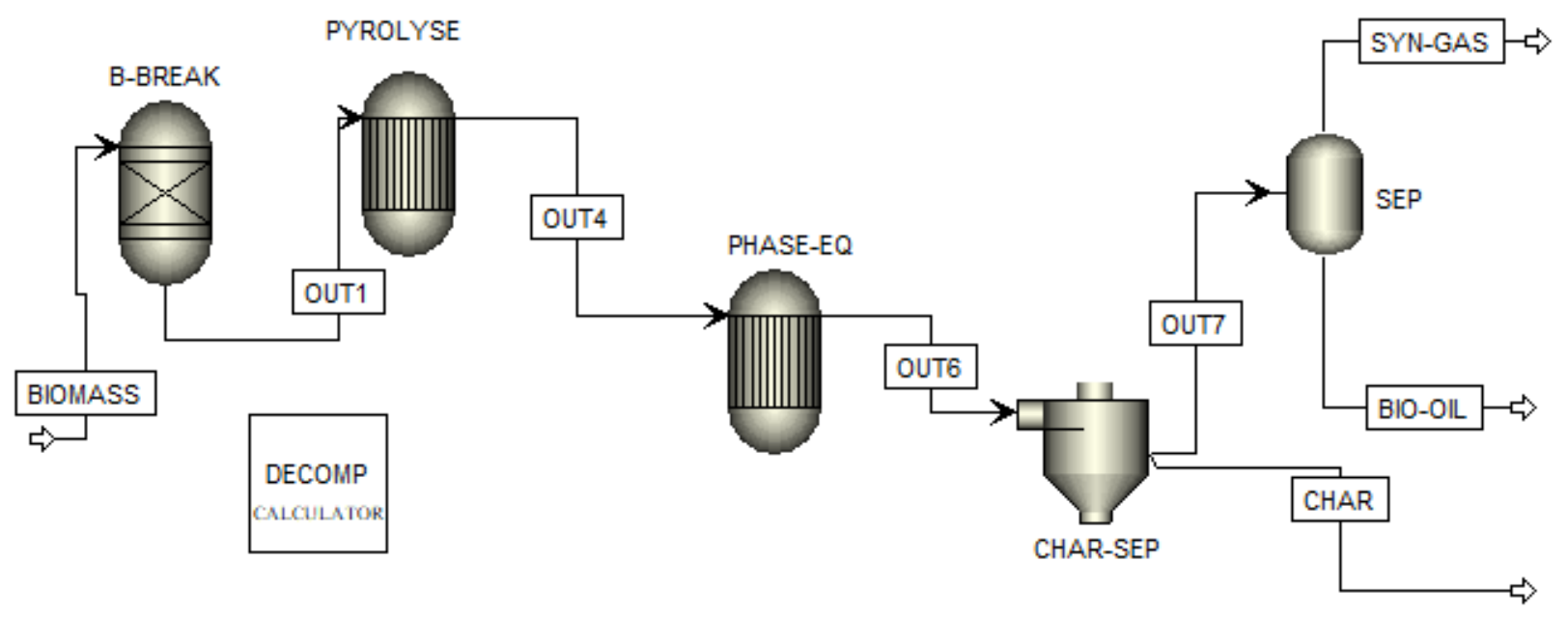

Figure 1. Process flow diagram for the pyrolysis simulation (Adeniyi et al., 2019e)

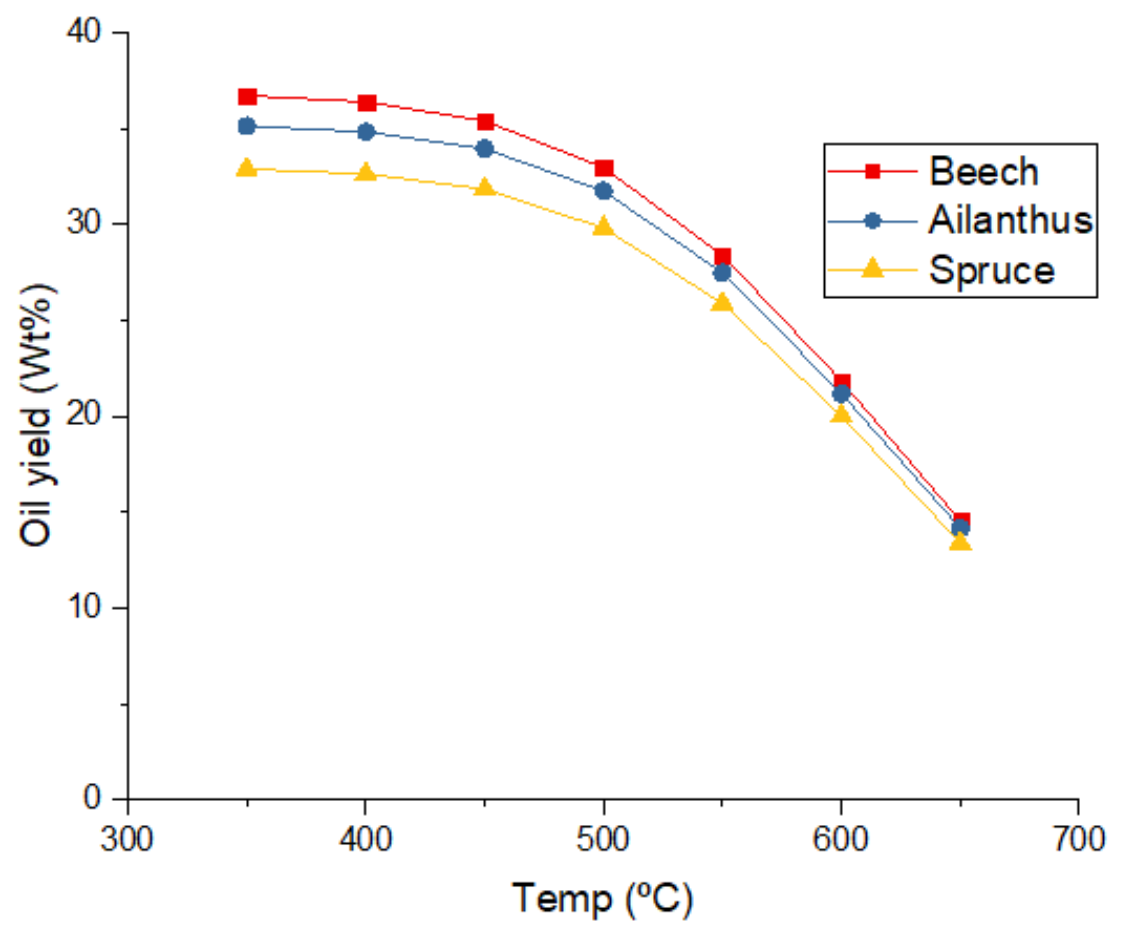

Figure 2. Temperature sensitivity of wood pyrolysis oil yield

\section{RESULTS AND DISCUSSION}

The simulation was successfully run on ASPEN Plus v8.8 and there were no errors in computation. This informs that the process integration was done accurately. The temperature sensitivity of different product species was examined. Beech wood is hardwood; Ailanthus wood is a soft hardwood while spruce is a softwood (Adeniyi and Ighalo, 2019a). In the discussion approach, the comparison of the three considered wood types are evaluated as the utilised modelling approach (Adeniyi et al., 2019e) takes into cognisance the differences in cellulose, hemicellulose and lignin content of the biomass. In describing the product streams, their composition is consistent with those of real systems. The bio-oil stream was composed of alcohols, aldehydes, organic acids and pyrolytic water. The gaseous product stream was composed of methane, hydrogen, carbon monoxide and some water vapour while the bio-char stream was composed of carbon and silicon oxide ash.

\section{Bio-oil Yield}

Figure 2 shows the sensitivity of bio-oil yield to temperature for the pyrolysis of Beech, Ailanthus and Spruce. It can be observed from the figure that the yield of bio-oil reduces gradually from $350^{\circ} \mathrm{C}$ to about $450^{\circ} \mathrm{C}$ and drops drastically beyond that point. This is typical of pyrolysis systems as the increase in temperature leads to the more intense thermal cracking and breakdown of the compounds in the reactor which leads to a lesser proportion of oil-range liquid-phase compounds. Below $350^{\circ} \mathrm{C}$ is 


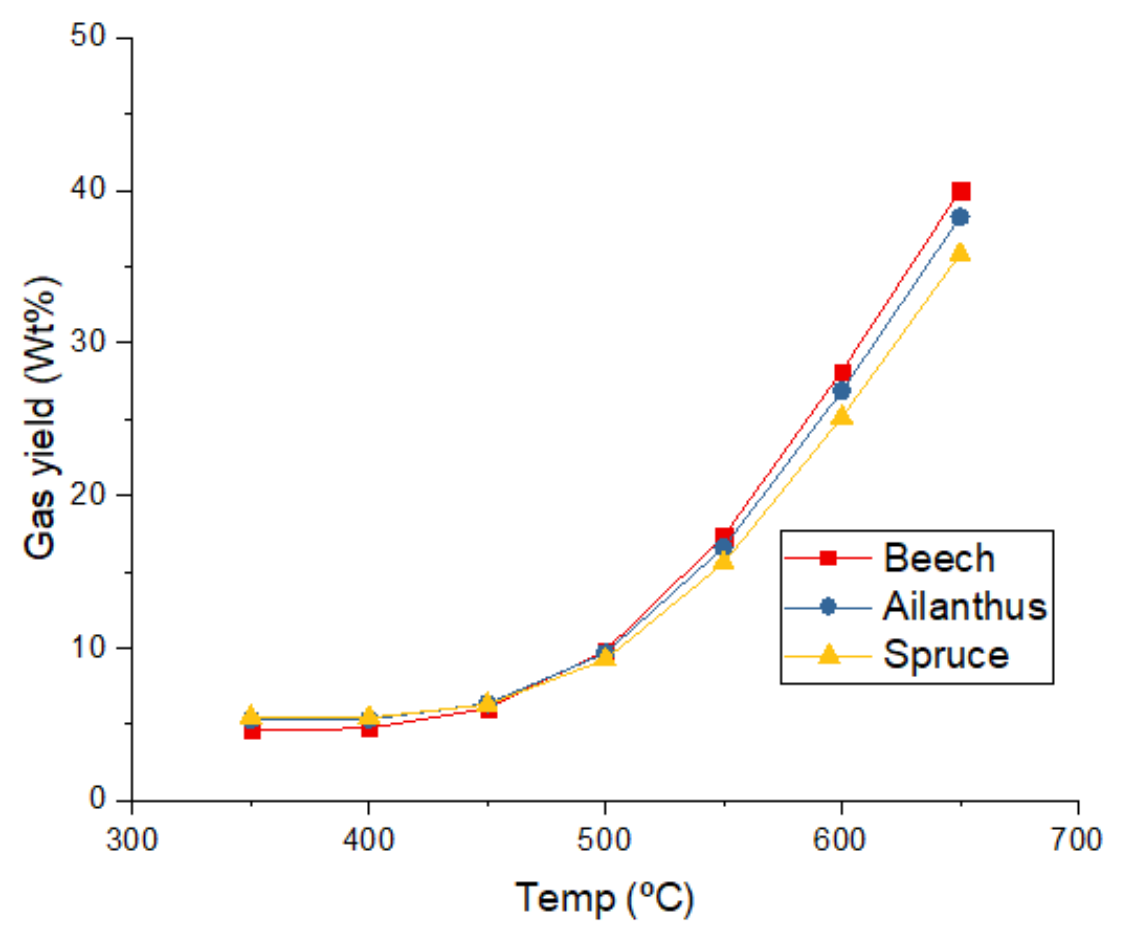

Figure 3. Temperature sensitivity of wood pyrolysis gas yield

characterised by free radical formation, water elimination and depolymerisation (Jahirul et al., 2012), while between $350^{\circ} \mathrm{C}$ and $450^{\circ} \mathrm{C}$ is characterised by the breaking of the glycosidic linkages of the tar fraction while above $450^{\circ} \mathrm{C}$ is characterised by a combination of all above processes. It can also be observed that the oil prediction is higher for beech (hardwood) than for ailanthus (soft hardwood) and then the least is spruce (softwood). The differences are however greater at the lower temperature range. At $350^{\circ} \mathrm{C}$, oil yield was $36.72 \%, 35.13 \%$ and $32.89 \%$ for beech, ailanthus and spruce respectively while at $650^{\circ} \mathrm{C}$, oil yield was $14.55 \%$, $14.17 \%$ and $13.39 \%$ for the three biomasses respectively. The temperature effect on oil yield is similar to those observed in other studies albeit for banana residues (Ighalo and Adeniyi, 2019), switchgrass (Ighalo and Adeniyi, 2020), and poultry litter (Adeniyi et al., 2019d). Though oil yield was observed to be higher for hardwood than for the others the difference is not quite large. The maximum difference in yield (about 5\%) was achieved at the optimum temperature with greater similarity in value being observed at lower oil yield.

\section{Syn-gas Yield}

Figure 3 shows the sensitivity syn-gas yield to temperature for the pyrolysis of Beech, Ailanthus and Spruce. A gradual rise in the gas yield was initially observed between $350^{\circ} \mathrm{C}$ and $450^{\circ} \mathrm{C}$ and then it becomes drastic beyond that point. As explained in the earlier section, the more intense thermal breakdown and cracking of the compounds in the reactor at higher temperatures lead to a greater portion of lighter gaseous-phase chemical species. There is not much difference in the gas yield between the wood samples at low temperatures but the at $650^{\circ} \mathrm{C}$, the gas yield was $39.99 \%, 38.25 \%$ and $35.82 \%$ for beech (hardwood), ailanthus (soft hardwood) and spruce (softwood) respectively. The yield of volatiles (bio-oil and syn-gas) is higher for the hard and soft hardwood than for the softwood. The temperature effect on gas yield is in agreement with the observations in other studies albeit for banana residues (Ighalo and Adeniyi, 2019), switchgrass (Ighalo and Adeniyi, 2020), and poultry litter (Adeniyi et al., 2019d).

\section{Bio-char Yield}

Figure 4 shows the temperature sensitivity of char yield for Beech, Ailanthus and Spruce. For the entirety of the temperature range studied, a gentle fall in char yield is observed for a wood species (though more significant at temperatures above $500^{\circ} \mathrm{C}$ ). At higher temperatures, the formation of the carbonyl compounds (such as acrolein, glyoxal and acetaldehyde) do occur (Jahirul et al., 2012) which leads to the drop in char yield. It can also be observed from the figure that the yield of char from spruce (softwood) is higher than for ailanthus (soft hardwood) and beech (hardwood). This is the direct opposite of the observed trend for the fluid products but is expected as all yields must sum up to $100 \%$. At $650^{\circ} \mathrm{C}$ for example, the char yield was $45.44 \%, 47.58 \%$ and $50.77 \%$ for beech (hardwood), ailanthus (soft hardwood) and spruce (softwood) respectively. The temperature effect on char yield is similar to those observed in other studies albeit for banana residues (Ighalo and Adeniyi 2019), switchgrass (Ighalo and Adeniyi, 2020), and poultry litter (Adeniyi et al., 2019d). 


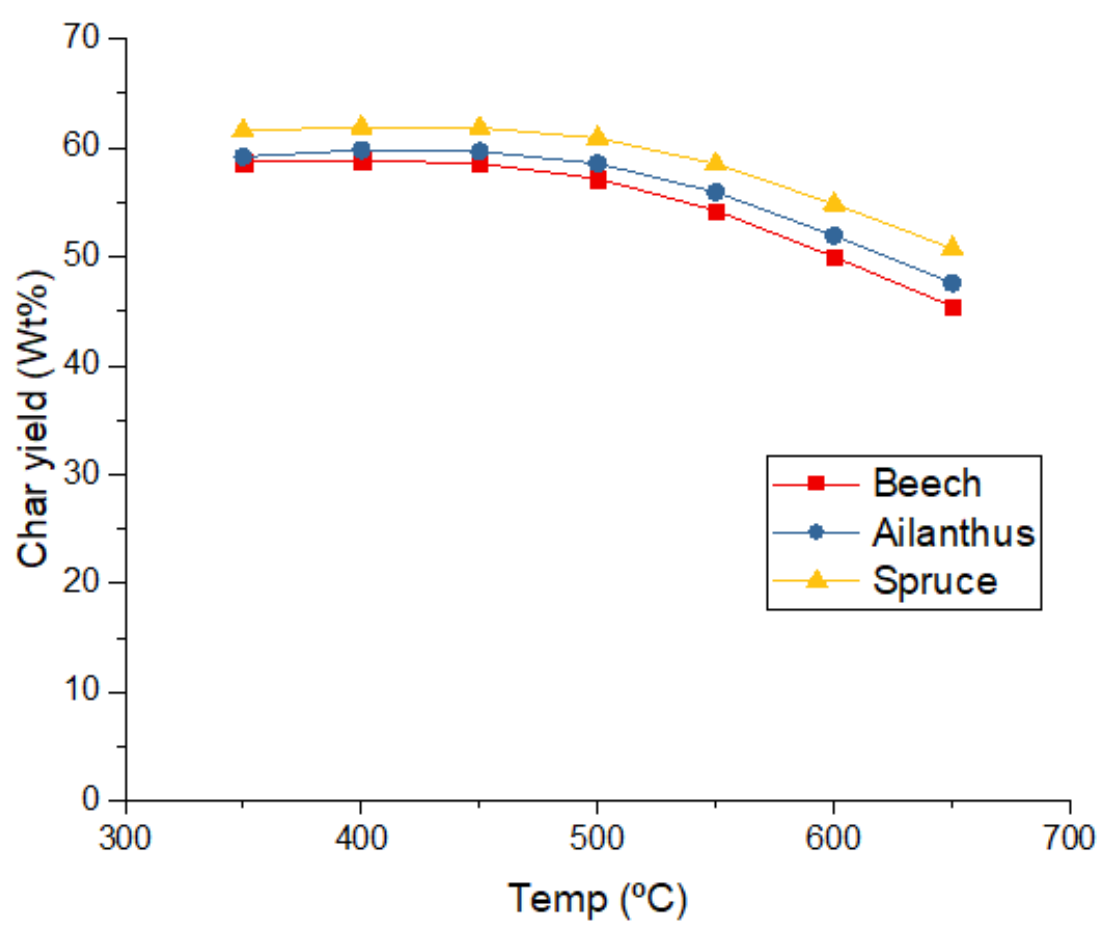

Figure 4. Temperature sensitivity of wood pyrolysis char yield

\section{CONCLUSION}

Upon the successful development of the model on ASPEN Plus v8.8, the analysis of temperature sensitivity of different product species in the pyrolysis of beech (hardwood), ailanthus (soft hardwood) and spruce (softwood) was examined. It was observed that oil yield fell with temperature with the Beech having the highest yield over the domain of the temperature range studied. At $350^{\circ} \mathrm{C}$, oil yield was $36.72 \%, 35.13 \%$ and $32.89 \%$ for beech, ailanthus and spruce respectively while at $650^{\circ} \mathrm{C}$, oil yield was $14.55 \%$, $14.17 \%$ and $13.39 \%$ for the three biomasses respectively. A gradual rise in the gas yield was initially observed between $350^{\circ} \mathrm{C}$ and $450^{\circ} \mathrm{C}$ and then it becomes drastic beyond that point. At $650^{\circ} \mathrm{C}$, the gas yield was $39.99 \%, 38.25 \%$ and $35.82 \%$ for beech (hardwood), ailanthus (soft hardwood) and spruce (softwood) respectively. For the entirety of the temperature range studied, a gentle fall in char yield is observed for a wood species (though more significant at temperatures above $500^{\circ} \mathrm{C}$ ). At $650^{\circ} \mathrm{C}$ for example, the char yield was $45.44 \%, 47.58 \%$ and $50.77 \%$ for beech, ailanthus and spruce respectively. It was observed that the yield of volatiles (bio-oil and syn-gas) is higher for the hard and soft hardwood than for the softwood and this is vice versa for the char yield. This study has helped gain some insight into the process systems engineering of hard and softwood pyrolysis systems.

\section{REFERENCES}

Abdelouahed, L., Authier, O., Mauviel, G., Corriou, J.-P., Verdier, G. and Dufour, A. (2012). Detailed modeling of biomass gasification in dual fluidized bed reactors under Aspen Plus. Energy \& Fuels, 26(6), 3840-3855. https://doi.org/10.1021/ef300411k

Adeniyi, A. G. and Ighalo, J. O. (2019a). Aspen Plus Predictive Simulation of Soft and Hard Wood Pyrolysis for Bio-Energy Recovery. International Journal of Environment and Waste Management, 26(2), 234-244. https://doi.org/10.1504/ijewm.2020.10028695

Adeniyi, A. G. and Ighalo, J. O. (2019b). A review of steam reforming of glycerol. Chemical Papers, 73, $2619-2635$. https://doi.org/10.1007/s11696-019-00840-8

Adeniyi, A. G. and Ighalo, J. O. (2020). Computer-Aided Modeling of Thermochemical Conversion Processes for Environmental Waste Management. In: C. M. Hussain (ed) Handbook of Environmental Materials Management (pp 1-16). Springer Nature, Switzerland. https://doi.org/10.1007/978-3-319-58538-3_185-1

Adeniyi, A. G., Ighalo, J. O. and Abdulsalam, A. (2019a). Modelling of Integrated Processes for the Recovery of the Energetic Content of Sugarcane Bagasse. Biofuels, Bioproducts \& Biorefining, 13, 1057-1067. https://doi.org/10.1002/bbb.1998

Adeniyi, A. G., Ighalo, J. O. and Aderibigbe, F. A. (2019b). Modelling of integrated processes for the pyrolysis and steam reforming of rice husk (Oryza sativa). SN Applied Sciences, 1, 841. https://doi.org/10.1007/s42452-019-0877-6

Adeniyi, A. G., Ighalo, J. O. and Amosa, K. M. (2019c). Modelling and simulation of banana (Musa spp.) waste pyrolysis for bio-oil production. Biofuels. Published online: 30 Jan 2019. https://doi.org/10.1080/17597269.2018.1554949

Adeniyi, A. G., Ighalo, J. O., Onifade, D. V. and Adeoye, A. S. (2019d). Modelling the Valorisation of Poultry Litter Via Thermochemical Processing. Biofuels, Bioproducts \& Biorefining, 14(2), 242-248. https://doi.org/10.1002/bbb.2056 
Adeniyi, A. G., Odetoye, T. E., Titiloye, J. and Ighalo, J. O. (2019e). A Thermodynamic Study Of Rice Husk (Oryza Sativa) Pyrolysis. European Journal of Sustainable Development Research, 3(4), em0094. https://doi.org/10.29333/ejosdr/5830

Adeniyi, A. G., Otoikhian, K. S. and Ighalo, J. O. (2019f). Steam Reforming of Biomass Pyrolysis Oil: A Review. International Journal of Chemical Reactor Engineering, 17(4), 20180328. https://doi.org/10.1515/ijcre-2018-0328

Arregi, A., Lopez, G., Amutio, M., Barbarias, I., Bilbao, J. and Olazar, M. (2016). Hydrogen production from biomass by continuous fast pyrolysis and in-line steam reforming. RSC Advances, 6, 25975-25985. https://doi.org/10.1039/C6RA01657J

Asmadi, M., Kawamoto, H. and Saka, S. (2011). Gas-and solid/liquid-phase reactions during pyrolysis of softwood and hardwood lignins. Journal of Analytical and Applied Pyrolysis, 92(2), 417-425. https://doi.org/10.1016/j.jaap.2011.08.003

Block, C., Ephraim, A., Weiss-Hortala, E., Minh, D. P., Nzihou, A. and Vandecasteele, C. (2018). Co-pyrogasifcation of Plastics and Biomass, a Review. Waste and Biomass Valorization, 10, 483-509. https://doi.org/10.1007/s12649-018-0219-8

Collard, F.-X. and Blin, J. (2014). A review on pyrolysis of biomass constituents: Mechanisms and composition of the products obtained from the conversion of cellulose, hemicelluloses and lignin. Renewable and Sustainable Energy Reviews, 38, 594-608. https://doi.org/10.1016/j.rser.2014.06.013

Dabiri Atashbeyk, M., Shahbazi, K. and Fattahi, M. (2018). Pressure Profile Estimation through CFD in UBD Operation Considering with Influx to Wellbore. Iranian Journal of Chemistry and Chemical Engineering (IJCCE), 37(92), 271-283.

Darvishi, A., Davand, R., Khorasheh, F. and Fattahi, M. (2016). Modeling-based optimization of a fixed-bed industrial reactor for oxidative dehydrogenation of propane. Chinese Journal of Chemical Engineering, 24(5), 612-622. https://doi.org/10.1016/j.cjche.2015.12.018

Demirbaş, A. (1997). Calculation of higher heating values of biomass fuels. Fuel, 76(5), 431-434. https://doi.org/10.1016/S00162361(97)85520-2

Di Blasi, C. (2008). Modeling chemical and physical processes of wood and biomass pyrolysis. Progress in energy and combustion science, 34(1), 47-90. https://doi.org/10.1016/j.pecs.2006.12.001

Emadi, B., Iroba, K. L. and Tabil, L. G. (2017). Effect of polymer plastic binder on mechanical, storage and combustion characteristics of torrefied and pelletized herbaceous biomass. Applied Energy, 198, 312-319. https://doi.org/10.1016/j.apenergy.2016.12.027

Gani, A. and Naruse, I. (2007). Effect of cellulose and lignin content on pyrolysis and combustion characteristics for several types of biomass. Renewable Energy, 32(4), 649-661. https://doi.org/10.1016/j.renene.2006.02.017

Goyal, H., Seal, D. and Saxena, R. (2008). Bio-fuels from thermochemical conversion of renewable resources: a review. Renewable and Sustainable Energy Reviews, 12(2), 504-517. https://doi.org/10.1016/j.rser.2006.07.014

Gu, H., Tang, Y., Yao, J. and Chen, F. (2018). Study on biomass gasification under various operating conditions. Journal of energy institute, 92(5), 1329-1336. https://doi.org/10.1016/j.joei.2018.10.002

Hosseinpour, S., Aghbashlo, M. and Tabatabaei, M. (2018). Biomass higher heating value (HHV) modeling on the basis of proximate analysis using iterative network-based fuzzy partial least squares coupled with principle component analysis (PCA-INFPLS). Fuel, 222, 1-10. https://doi.org/10.1016/j.fuel.2018.02.126

Ighalo, J. O. and Adeniyi, A. G. (2019). Thermodynamic modelling and temperature sensitivity analysis of banana (Musa spp.) waste pyrolysis. SN Applied Sciences, 1, 1086. https://doi.org/10.1007/s42452-019-1147-3

Ighalo, J. O. and Adeniyi, A. G. (2020). Modelling of thermochemical energy recovery processes for switchgrass (Panicum virgatum). Indian Chemical Engineer. Published online 20 Jan 2020. https://doi.org/10.1080/00194506.2020.1711535

Jahirul, M. I., Rasul, M. G., Chowdhury, A. A. and Ashwath, N. (2012). Biofuels production through biomass pyrolysis-a technological review. Energies, 5(12), 4952-5001. https://doi.org/10.3390/en5124952

Kan, T., Strezov, V. and Evans, T. J. (2016). Lignocellulosic biomass pyrolysis: A review of product properties and effects of pyrolysis parameters. Renewable and Sustainable Energy Reviews, 57, 1126-1140. https://doi.org/10.1016/j.rser.2015.12.185

Khadem-Hamedani, B., Yaghmaei, S., Fattahi, M., Mashayekhan, S. and Hosseini-Ardali, S. M. (2015). Mathematical modeling of a slurry bubble column reactor for hydrodesulfurization of diesel fuel: Single-and two-bubble configurations. Chemical Engineering Research and Design, 100, 362-376.

Licker, D. M. (2003). Dictionary of Engineering (2nd edn.). Chicago: Mc-Graw Hill Publishers.

Mohan, D., Pittman, C. U. and Steele, P. H. (2006). Pyrolysis of wood/biomass for bio-oil: a critical review. Energy \& Fuels, 20(3), 848889. https://doi.org/10.1021/ef0502397

Moradi, F., Kazemeini, M. and Fattahi, M. (2014). A three dimensional CFD simulation and optimization of direct DME synthesis in a fixed bed reactor. Petroleum Science, 11, 323-330. https://doi.org/10.1007/s12182-014-0347-0

Onarheim, K., Solantausta, Y. and Lehto, J. (2014). Process simulation development of fast pyrolysis of wood using aspen plus. Energy \& Fuels, 29(1), 205-217. https://doi.org/10.1021/ef502023y

Peters, J. F., Iribarren, D. and Dufour, J. (2013). Predictive pyrolysis process modelling in Aspen Plus. In: 21st Eur biomass conf exhib (pp. 923-927). https://doi.org/10.5071/21stEUBCE2013-2CV.4.8

Peters, J. F., Iribarren, D. and Dufour, J. (2015). Simulation and life cycle assessment of biofuel production via fast pyrolysis and hydroupgrading. Fuel, 139, 441-456. https://doi.org/10.1016/j.fuel.2014.09.014 
Qu, T., Guo, W., Shen, L., Xiao, J. and Zhao, K. (2011). Experimental Study of Biomass Pyrolysis Based on Three Major Components: Hemicellulose, Cellulose, and Lignin. Industrial \& Engineering Chemistry Research, 50(18), $10424-10433$. https://doi.org/10.1021/ie1025453

Santamaria, L., Lopez, G., Arregi, A., Amutio, M., Artetxe, M., Bilbao, J. and Olazar, M. (2018). Influence of the support on Ni catalysts performance in the in-line steam reforming of biomass fast pyrolysis derived volatiles. Applied Catalysis B: Environmental, 229, 105-113. https://doi.org/10.1016/j.apcatb.2018.02.003

Sharma, A., Pareek, V. and Zhang, D. (2015). Biomass pyrolysis-A review of modelling, process parameters and catalytic studies. Renewable and Sustainable Energy Reviews, 50, 1081-1096. https://doi.org/10.1016/j.rser.2015.04.193

Sinha, S., Jhalani, A., Ravi, M. and Ray, A. (2000). Modelling of pyrolysis in wood: A review. SESI Journal, 10, 41-62.

Torabi, A., Kazemeini, M. and Fattahi, M. (2016). Developing a mathematical model for the oxidative dehydrogenation of propane in a fluidized bed reactor. Asia - Pacific Journal of Chemical Engineering, 11(3), 448-459. https://doi.org/10.1002/apj.1966

Valle, B., Aramburu, B., Benito, P. L., Bilbao, J. and Gayubo, A. G. (2018). Biomass to hydrogen-rich gas via steam reforming of raw bio-oil over Ni/La 2 O 3-aAl 203 catalyst: Effect of space-time and steam-to-carbon ratio. Fuel, 216, 445-455. https://doi.org/10.1016/j.fuel.2017.11.151 